\title{
Fever in a patient with common cold and Brugada syndrome, what should we do?
}

Keywords: brugada syndrome, potential triggers, psychotropic drugs, anesthetic agents, cocaine, excessive alcohol, fever, shock, consciousness, headache, coughing, sneezing, malaise, autosomal dominant inherited disorder, ventricular arrhythmias, diagnosis, arrhythmia unit, propranolol, sodium channels, output potassium, electric ICD

\section{Introduction}

Brugada syndrome is characterized by a coved type ST-segment of $\geq 2 \mathrm{~mm}$ with a negative or flattened $\mathrm{T}$ wave in the precordial leads (V1-V3) and an increased risk of potentially fatal ventricular tachyarrhythmia's episodes. ${ }^{1,2}$ Several potential triggers of ventricular arrhythmias have been described, such as the use of some psychotropic drugs, anesthetic agents, cocaine, excessive alcohol intake or fever. ${ }^{3}$

\section{Clinical case}

A 27-years-old male patient, diagnosed with Brugada syndrome (Figure 1) clinically debut with cardiac arrest in ventricular fibrillation. In 2009 an implantable cardioverter defibrillator (ICD) was placed in a context of secondary prevention. In a 3 years period it has adequately addressed several episodes of malignant ventricular arrhythmias
Volume 2 Issue 6 - 2018

Puga Bravo Marcelo

Resident Cardiologist, Cardiovascular Institute of Havana, Cuba

Correspondence: Marcelo Puga Bravo, Cardiovascular Institute of Havana, $\mathrm{C}$ street $\mathrm{N}^{\circ} 206$ between 9 street and II street. Plaza de la revolución, Cuba, Tel +53 58500I38, Email marcalopuga@hotmail.es

Received: May 07, 2018 | Published: November 20, 2018

(ventricular fibrillation and polymorphic ventricular tachycardia). In the last 3 years he has not presented events registered by the device and he has remained under treatment with quinidine and propranolol. Two days ago he begins to present some symptoms related to common cold (headache, coughing, sneezing, malaise), with a temperature of $38.5^{\circ} \mathrm{C}$. Approximately one hour later, he had palpitations, felt an electric ICD shock and suddenly lost consciousness with complete recovery within a few seconds. When he was valued in an arrhythmia unit, the diagnosis of appropriate ICD shock was made.

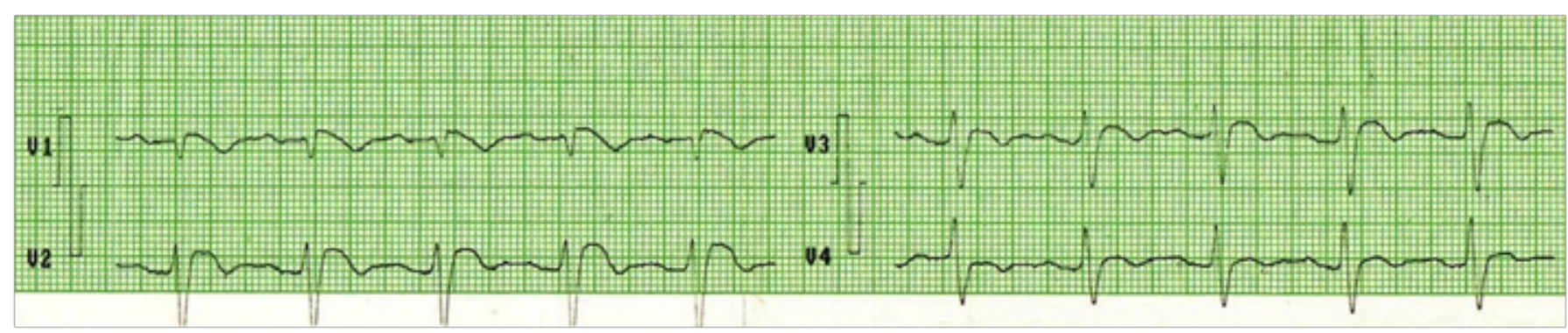

Figure I Electrocardiogram showing the Brugada sign (coved pattern) in the right precordial leads (VI-V3).

\section{Discussion}

The Brugada syndrome is an autosomal dominant inherited disorder with incomplete or variable penetrance. Linked to mutations in 19 different genes especially in the SCN5A. ${ }^{4}$ These mutations cause a function loss of ion current input especially inactivating sodium channel (INa) which further enhance the ionic currents output potassium. ${ }^{2}$ Inactivating sodium channel has also been associated with changes in body temperature and in several studies have demonstrated the association between febrile conditions and the appearance of its characteristic electrocardiographic pattern, increased ST segment elevation or even the presence of ventricular arrhythmias. ${ }^{5-7}$ As mentioned above the current literature recommend early and aggressively treatment of any febrile episode in patients with this syndrome..$^{3-8}$

\section{Acknowledgements}

None.

\section{Conflict of interest}

The auhtor declares there is no conflict of interest.

\section{References}

1. Brugada P, Brugada J. Right bundle branch block, persistent ST segment elevation and sudden cardiac death: a distinct clinical and electrocardiographic syndrome. A multicenter report. $J$ Am Coll Cardiol. 1992;20(6):1391-1396.

2. Antzelevitch C, Yan GX. J-wave syndromes: Brugada and early repolarization syndromes. Heart Rhythm. 2015;12(8):1852-1866.

3. Al-Khatib S, Stevenson W, Ackerman M, et al. 2017 AHA/ACC/HRS Guideline for Management of Patients With Ventricular. Heart Rhythm. 2017;138(13): e272-e391.

4. Chen Q, Kirsch G, Zhang D, et al. Genetic basis and molecular mechanisms for idiopathic ventricular fibrillation. Nature. 1998;392(6673):293296. 
5. Dumaine R, Towbin J, Brugada P, et al. Ionic mechanism responsible for the electrocardiographic phenotype of the Brugada syndrome are temperature dependent. Circ Res. 1999;85(9):803-809.

6. González Rebollo JM, Hernández Madrid A, García Á, et al. Fibrilación ventricular recurrente durante un proceso febril en un paciente con síndrome de Brugada. Rev Esp Cardiol. 2000;53(5):755-757.
7. Saura D, García-Alberola A, Carrillo P, et al. Brugada-like electrocardiographic pattern induced by fever. PACE. 2002;25(5):856-859.

8. Andorin A, Behr E, Denjoy I. Impact of clinical and genetic findings on the management of young patients with Brugada syndrome. Heart Rhythm. 2016;13(6):1274-1282. 